\title{
¿Una violencia invisible? Las mujeres en los monumentos públicos
}

\author{
Elo Vega \\ Universidad de Castilla-La Mancha \\ elovegav@gmail.com
}

RESUMEN: El monumento es la expresión artística más explícitamente política. Su función principal consiste en legitimar el orden del presente a través de una invocación al pasado, para lo que recurre a unas formas estéticas poseedoras de un poderoso capital simbólico acumulado a lo largo de la historia. Una de las más persistentes características del monumento es la profusión en ellos de figuras femeninas. La crítica feminista permite revelar en ella la visión androcéntrica e ideológicamente interesada en que se sustentan. El modelo de mujer predominante en la estatuaria pública construye una imagen fija, pretendidamente universal, inalterable y a-histórica de las mujeres, unos discriminatorios estereotipos de género que los propios monumentos contribuyen a reforzar.

PALABRAS CLAVE: Escultura pública, Arte público, Monumentos, Feminismo, Estudios de género, Imagen femenina.

\section{An Invisible Violence? Women in Public Monuments}

ABSTRACT: A monument is the most politically explicit artistic expression. Its main function is to legitimize the order of its time, and this is accomplished by using aesthetic forms that posses a powerful symbolic capital accumulated throughout history. One of the most persistent characteristics of the monuments is the profusion of female figures in them. The feminist critique is able to reveal the androcentric and ideologically interested nature that underpins this vision. The predominant female model in public statuary builds a fixed, allegedly universal, unchanging and anhistorical image of women: discriminatory gender stereotypes that monuments themselves reinforce.

KEYWORDS: Public Sculpture, Public Art, Monuments, Feminism, Gender Studies, Female Image.

Recibido: 12 de abril de 2016 / Aceptado: 29 de julio de 2016.

La cosa más sorprendente de los monumentos es que nunca los vemos. Nada en el mundo es tan invisible.

Robert MusiL

¿Monumentos? ¿A qué cosa ha reducido el desarrollo urbano a los monumentos sino a objetos varados como restos de un naufragio olvidado en las plazas públicas o en medio del tráfico; meras rotondas en torno a las que girar sin posibilidad alguna, desde el coche, de reparar en ellos? (Duque, 2001: 113). Los monumentos, se diría, son hoy, en efecto, invisibles. Pero la cita de Robert Musil con que se abre este texto data del primer tercio del siglo XX; la invisibilidad a la que se refiere responde a otros motivos que a la invasión de la ciudad moderna por el coche. El monumento, que ha sido históricamente un medio privilegiado para la transmisión de mensajes ideológicos, aspira, por definición, a la transparencia; su aparente invisibilidad se debe a la continuidad de su presencia, a que su exposición constante e invariable hace que su significado, por la fuerza del hábito, llegue a hacerse imperceptible.

VEGA, Elo: «¿Una violencia invisible? Las mujeres en los monumentos públicos», Boletín de Arte, n. ${ }^{\circ} 37$, Departamento de Historia del Arte, Universidad de Málaga, 2016, pp. 213-225, ISSN: 0211-8483. 


\section{EL PAIS DE LA OLLA.}

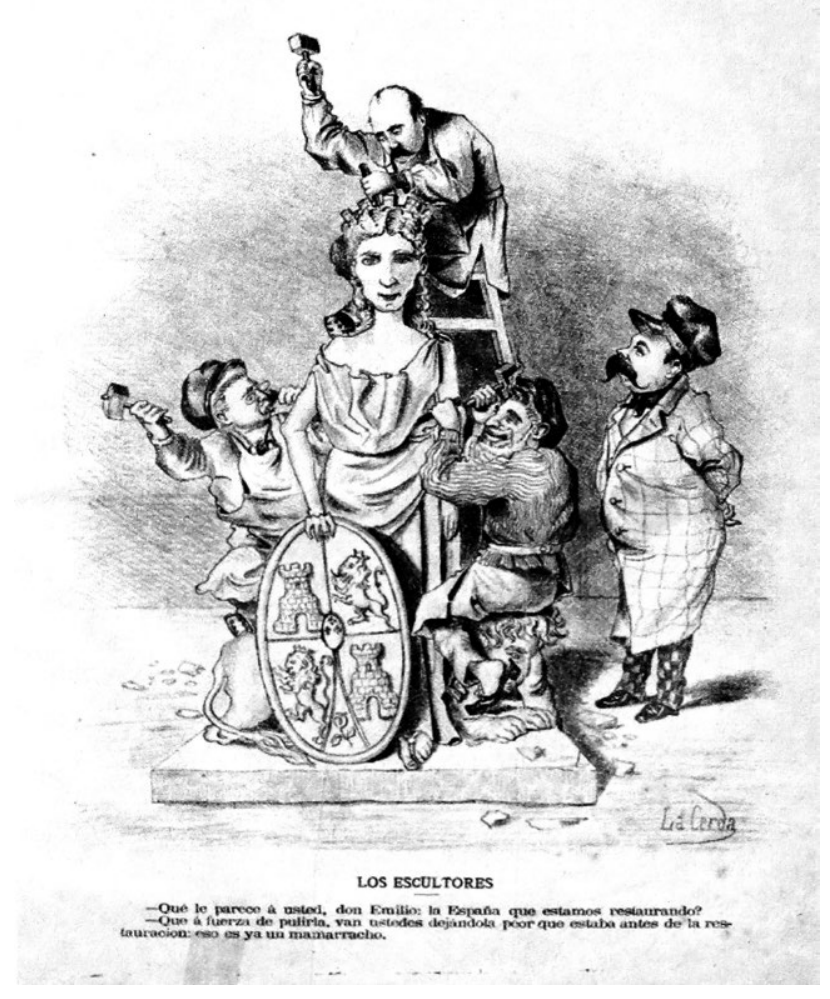

1. Los escultores, Emilio de la Cerda. El País de la Olla, 1882, Archivo Municipal de Málaga

Y es eso lo que lo convierte en un vehículo ideal de contenidos ideológicos: su presencia «naturalizada» en nuestra vida cotidiana, en los lugares centrales del espacio público, reproduce de modo sutilmente repetitivo, mediante actitudes, comportamientos y poses, "estetizadas" jerarquías y discriminaciones de género. Los monumentos, como señala el historiador Peter Burke, no solo guardan memoria de unos personajes o acontecimientos, sino que influyen de modo determinante en la forma en que esos hechos o personajes son percibidos, por lo tanto, producen sentido (2005: 183). El monumento aspira a ser eterno, busca dejar una huella del presente en el futuro, permanecer como un «legado a las generaciones futuras", exaltando la legitimidad de quienes ostentan el poder en el momento presente, que aparecen así como herederos naturales de las glorias del pasado.
El historiador Francisco Erice sostiene que la «estatuomanía» es uno de los más visibles signos de lo moderno y que nace como respuesta frente a «lo transitorio, lo fugitivo, lo contingente", que Baudelaire consigna como esencia de la modernidad. Una verdadera fiebre monumentalista recorrerá en el siglo XIX Europa y las repúblicas americanas en nombre de un culto a los "grandes hombres" que desborda el antiguo catálogo de santos y de reyes, resultando la más visible de «las políticas de memoria y la pedagogía social del liberalismo» (Erice, 2008: 123-125).

Y junto a los prohombres, a los «padres de la patria», que salvo contadas excepciones, son varones (representados en los monumentos según unos rasgos característicos -la fuerza o el valor-, respondiendo a un modelo de virilidad compartido con el imaginario militar: el héroe guerrero), la Nación puede ser imaginada, y de hecho así va a suceder por norma, como una hermosa mujer [1].

Desde la Revolución, Francia se erigió como referencia ideal de Estado nación, y no va a haber proyecto liberal que permanezca inmune a su influencia estética a la hora de proyectar la imagen de las nuevas naciones. A partir de la alegoría de la República, siempre una mujer joven semidesnuda, se construye el modelo que da cuerpo al concepto de nación, pero la «madre patria» -a diferencia de sus más ilustres hijos, paradójicamente conocidos como «padres de la patria»- no es una persona concreta; desde el mito fundacional de Roma, a partir del rapto de las sabinas, o aún más lejos, el rapto de Europa, el cuerpo femenino constituye un elemento indispensable de la maquinaria que produce la identidad colectiva (Durán, 2008: 70). Un imaginario del que no está en absoluto ausente la violencia contra las mujeres. Los más antiguos choques entre grupos humanos se originarían en torno a la disputa por los territorios de caza, pesca y recolección... y por la propiedad de las mujeres. Hasta el día de hoy la guerra incluye, como parte del territorio enemigo, el cuerpo de las mujeres (Segato, 2010: 41). Tanto para los pueblos como para los individuos, el cuerpo de las mujeres es un tablero sobre el que se dirime y donde se exhibe "quién manda aquí»". Como escribe Barbara Kruger en su célebre fotomontaje de 1989, «tu cuerpo es un campo de batalla» (Bordo, 1991: 120).

En el momento de la (re)invención de las naciones modernas, las élites volverán la mirada hacia las formas clásicas, que representan la edad de oro de la invención de la 


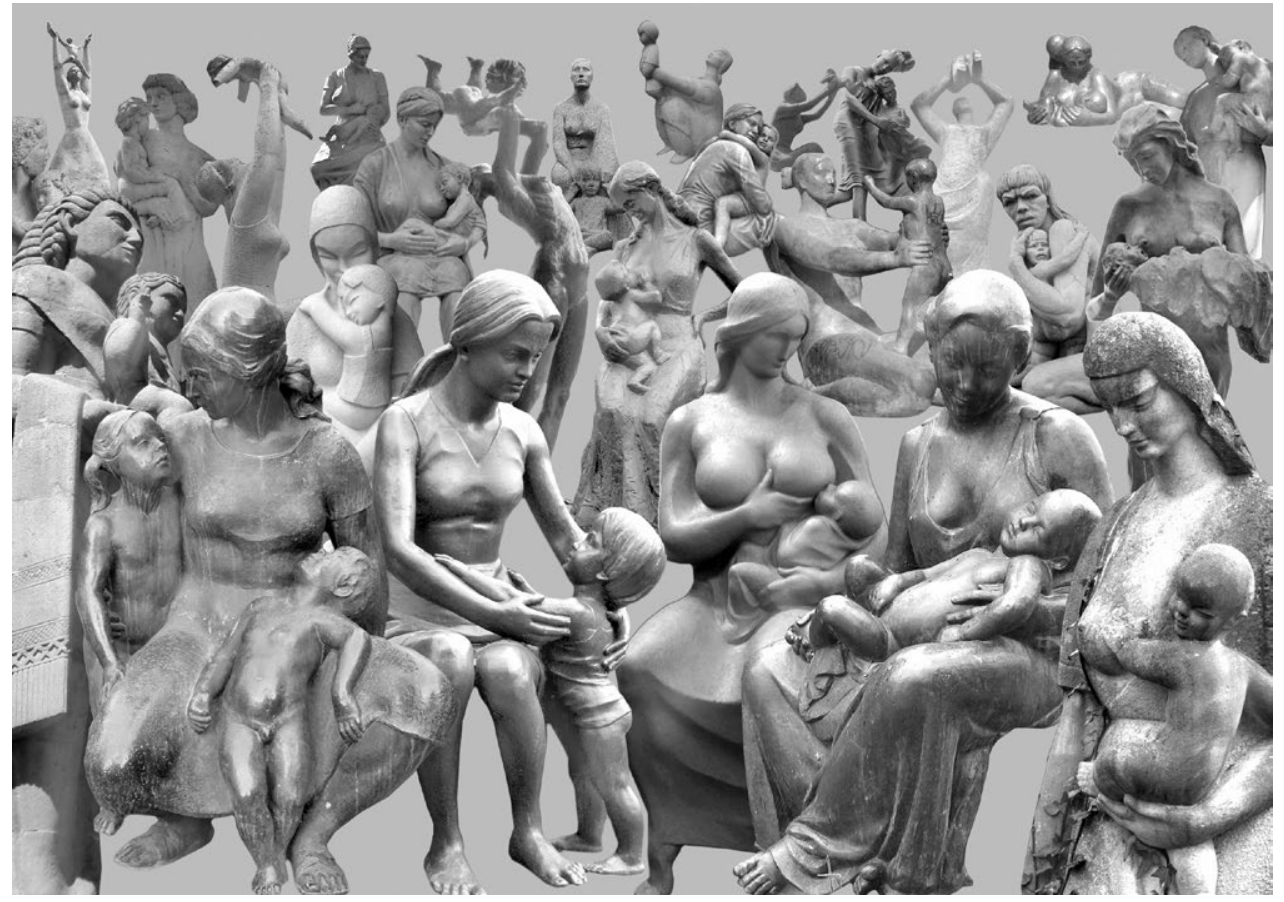

2. Colección I: Maternidades. Luis Ortiz Monasterio, 1949, México DF. Felix Reyes, 1974, Logroño. Félix Alonso Arena, 2003, Oviedo. Mater Natura, Miguel Moreno, 2006, Churriana de la Vega (Granada). Josep Clará Ayats, 1953, Olot (Gerona). Marino Amaya, 1960, Gijón. Melchor Zapata, 2009, Castellón de la Plana. David Paz Ramos, 1978, Santa Cruz (Bolivia). Joaquín García Donaire, 1998, Villaviciosa de Odón (Madrid). Encarna con Chiquilin, Sebastián Miranda, 2005, Oviedo/Maternidad de la Florida, Sebastián Miranda, 2010, Oviedo. Vida, Luis Sanguino, 1999, Oviedo. Marino Amaya, Almería. Años 70, Alcázar de San Juan (Ciudad Real). Carlos Rojas, Matanzas (Cuba). José Esteve Edo, 1955, Valencia. Jerez de la Frontera (Cádiz). Tizimín (Yucatán) México. Manuel Cusachs i Xivillé, 1967, Mataró. Marino Amaya, León. Scopia (República de Macedonia). Matteo Tonietti y Érico Gobbi, 1948, Río Grande do Sul. Brasil. 1963, Villajoyosa (Alicante). Monterrey (México). Lluis Curos Morató, 1970, Olot (Gerona)

democracia. Idealizadas mujeres desnudas van a poblar los templos de las nacientes naciones del XIX, pero esta destacada presencia de imágenes femeninas no va a significar la inclusión de las mujeres en los sitios de poder; al contrario, han sido sistemáticamente excluidas del ámbito donde tienen lugar las discusiones y las decisiones colectivas, la política de las naciones (Yuval-David, 2004: 13).

Las estatuas femeninas van a encarnar alegóricamente ideas abstractas (la libertad, la justicia, la ciencia, etc.) y también sentimientos (bondad, caridad, constancia, etc.), de preferencia relacionados con los afectos, destacando las referencias a la mujer como madre. $Y$, en efecto, junto a aquellas representaciones de la mujer en las que predomina su carácter erótico, las que proporcionan más abundancia de ejemplos van a ser aquellas en las que apa- recen en el papel de madre. Ambas facetas subrayan la escisión fundamental de las categorías «masculino» y «femenino» en el discurso patriarcal -y sus oposiciones binarias asociadas, activo-pasivo, espiritual-carnal, racional-pasional, etc.- que identifican a las mujeres esencialmente con lo «natural» [2].

En la lucha por la hegemonía ideológica, la dimensión cultural, y dentro de ella el control sobre las imágenes, tiene una importancia transcendental. Es aquí donde tiene que entenderse el mito de la madre como modelo de abnegación, de generosidad y de entrega. La sacralización del trabajo reproductivo, además de la crianza y el cuidado de los niños, la procura de alimentos y la administración de los recursos domésticos, incluye la transmisión de la cultura. Estas funciones, que se asignan de modo principal a las madres, no re- 


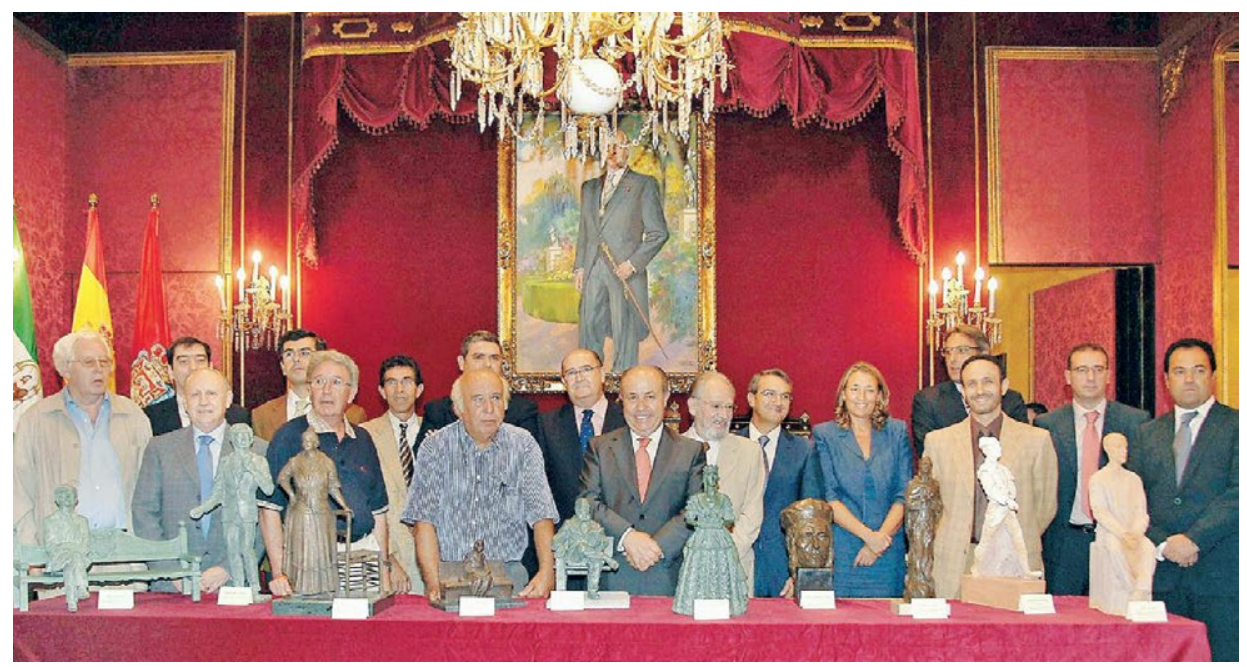

3. Salón de Plenos del Ayuntamiento de Granada durante la presentación de bocetos y la firma de contratos con los artistas para la realización de diez esculturas para instalarlas en el bulevar de la Constitución de Granada. Revista Paso a paso, octubre de 2008 ciben la misma valoración, el mismo valor que el trabajo productivo, ya que no generan ingresos económicos. Por esto, el control de la sexualidad y de la reproducción ha constituido y sigue siendo un asunto de vital interés para el sistema patriarcal, tanto en el terreno material como en el simbólico: el poder de la masculinidad se constituye precisamente como la conquista y dominación sobre las mujeres, y edifica las relaciones de género a través de un intricado andamiaje donde se trenzan las normatividades institucionales con la construcción de las subjetividades (González, 2014: 2).

La imagen más común y dominante de la madre en realidad nos dice poco sobre las mujeres, informando más bien de las fantasías y de los temores generados por la imaginación de los hombres, pues varones son quienes, por lo general, producen tales imágenes. $Y$ prácticamente todas las demás.

Acerca de la escasez de mujeres autoras de esculturas públicas es preciso señalar:

1) El corto número de artistas profesionales que ejercen en ese campo, a pesar de que el número de estudiantes mujeres en las enseñanzas artísticas es mayor que el de varones. La proverbial minoría de mujeres artistas reconocidas como autoras se agudiza en el caso de la escultura (tan viril ella, tradicionalmente exigente de esfuerzo físico, más que, por ejemplo, la pintura), y se lleva al extremo en el caso del monumento público.
2) El concepto de «genio». Linda Nochlin, en su célebre ensayo de 1971, Why Have There Been No Great Women Artists?, ha desmontado el proceso de construcción de la idea de arte como «una actividad autónoma y libre» por parte "de un individuo superdotado", el «genio» (2007: 28). Esta categoría que, a modo de aura, acompaña a los grandes artistas inmortalizados por la Historia, no contempla la inclusión de mujeres.

3) Estos «genios», en el caso de los autores de monumentos públicos, necesariamente tienen que ser también genios de la gestión de su propia marca, ya que ese tipo de práctica exige una presencia activa y una red de relaciones sociales en el ámbito de la Administración Pública, con los profesionales de la política, y con los empresarios que patrocinan el arte público -con frecuencia, las propias empresas constructoras-, ambientes todos ellos tradicionalmente masculinos. La adaptación a los gustos y las expectativas de esos sectores que realizan el encargo y lo que esperan del monumento, excluye de antemano prácticamente cualquier posibilidad, tanto de experimentación formal como de contenido mínimamente crítico. Las obras de arte público de adscripción monumental tienden a ser, por definición, estética e ideológicamente conservadoras. Esto explicaría la ausencia de perspectivas críticas de género en los monumentos, incluidos los pocos ejemplos de obras realizadas por mujeres artistas [3]. 


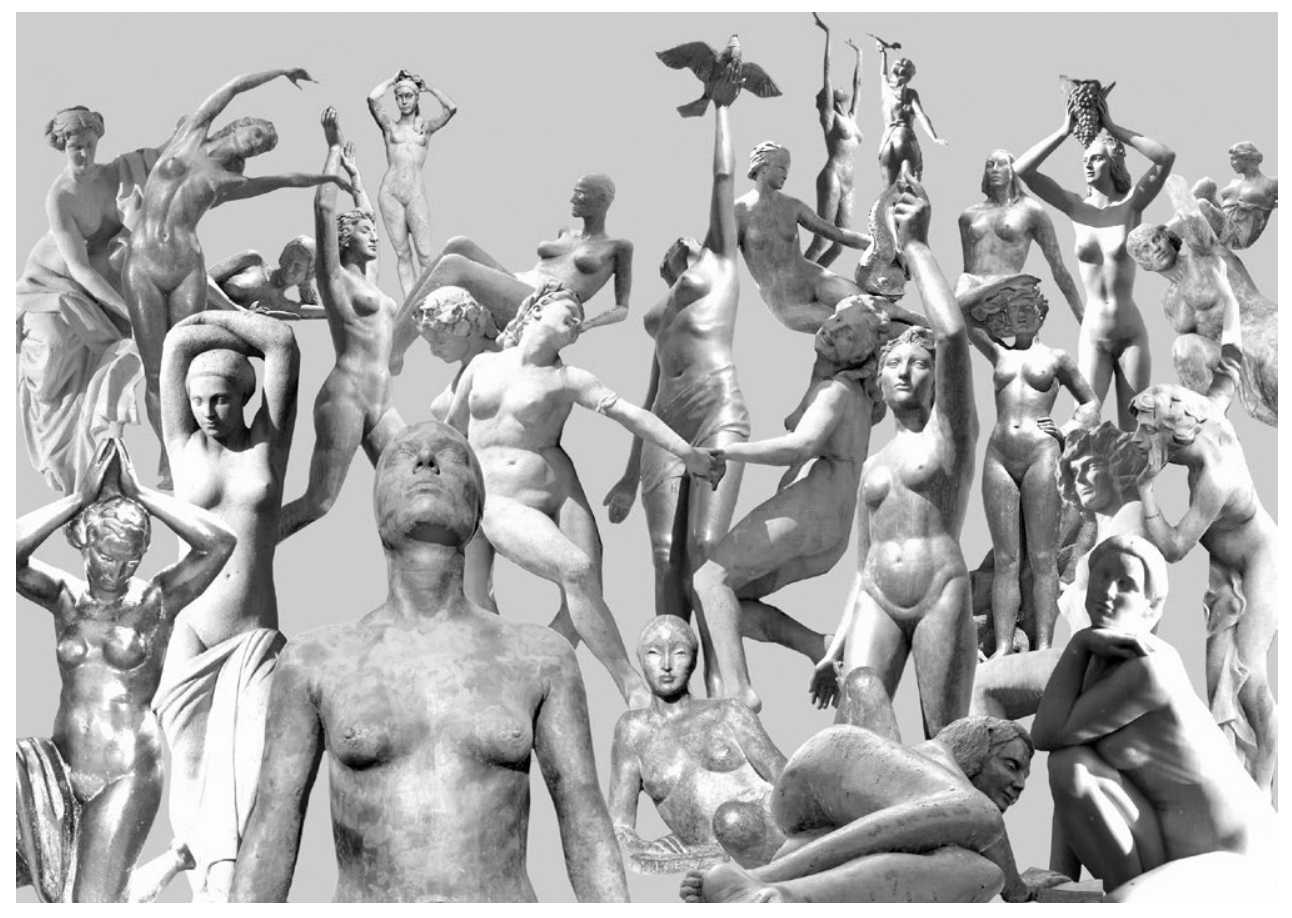

4. Colección II: Alegorías y desnudos femeninos. Mujer, Juan B. Adsuara, 1987, Castellón de la Plana. Juventud, Josep Clarà, 1928, Barcelona. Mujer, Antonio López, 2010, Coslada (Madrid). Mujer reclinada con libro, José Esteve Edo, 1978, Valencia. A la Generación de 1927, César Portela, 2011, Sevilla. La Diosa o L'Enigma, Josep Clarà, 1927, Barcelona. Alegorías, pedestal del monumento a Quevedo, Agustín Quero, 1902, Madrid. Mujer, Carlos Pérez de Albéniz Navarro, 1991, Zaragoza. Gadez, José Luis Vasallo, (1948), 1989, Cádiz. República, Josep Viladomat, 1936, Barcelona. Libertad, Basamento del monumento a Alfonso XII, Aniceto Marinas, 1922, Madrid. La Libertad, Salvador Amaya, 2003, Alcorcón (Madrid). Alegoría, Monumento a Ramón Gómez de la Serna, Enrique Pérez Comendador, 1972, Madrid. Danza, Josep Salvadó Jassans, 1986, Reus (Tarragona). Alegoría, Monumento a Juan Bravo Murillo, Miguel Ángel Trelles, 1902, Madrid. Fuente de la Juventud, Federico Coullant Valera, 1955, Madrid. Mujer, Luis Borrajo, 2002, Orense. Mujer, Frederic Marès, Portbou (Gerona). Alcanzar una estrella/Homenaje a la mujer, Jaime Pimentel, 2007, Vélez-Málaga (Málaga). Al sol, Francisco Bolinches Mahiques, 1962, Valencia. Musa del vino, Juan de Ávalos, Almendralejo (Badajoz). Comercio e Industria, en el monumento a Alfonso XII, José Clará Ayats, 1920, Madrid. La Navegación o la Marina mercante, en el monumento al primer marqués del Campo, Mariano Benlliure, 1908, Valencia

Lo cierto es que el poco arte público escultural realizado por mujeres no se distingue precisamente por rasgos que hagan sospechar en modo alguno su compromiso feminista o su conciencia de género, sino que, más bien, reproduce los tópicos del discurso androcéntrico dominante. Incluidos los casos en que el monumento incorpora figuras femeninas. La condición habitual entre las mujeres cuyos cuerpos, esculpidos en piedra o fundidos en bronce, decoran las fuentes y las plazas de nuestras ciudades es el anonimato: nadie sabe quiénes son. Lo normal es que se trate de figuras alegóricas, ocupando un plano secundario, complementario con respecto al asunto central del monumento, y con frecuencia desnudas [4].

El desnudo es el tema más común en el arte de Occidente. El Renacimiento hizo de él un género tan básico en la pintura y la escultura que se llegó a considerar, y aún en ciertos círculos hoy día lo sigue siendo, como un arte en sí mismo. La teoría feminista del arte ha realizado una minuciosa relectura de la diferente evolución del significado del desnudo femenino y el masculino a lo largo de la historia ${ }^{3}$. El desnudo pintado o esculpido constituye una de las idealizaciones más persistentes del cuerpo femenino. La Historia del 


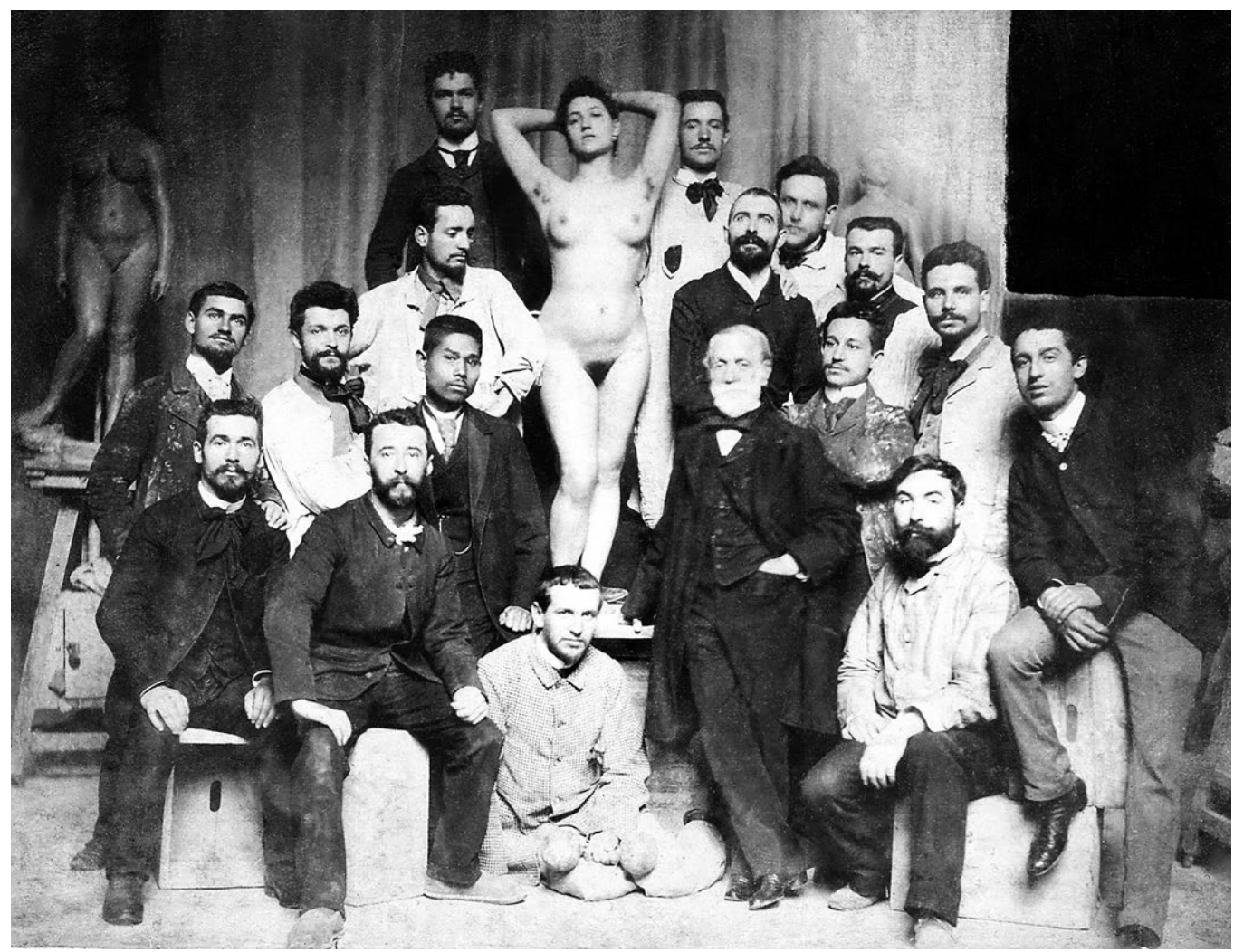

5. Taller de Jules Cavalier, alrededor de 1900, París
Arte ha transmitido las convenciones de una feminidad legitimada por la obra de los grandes maestros; una tradición que pervive en el desnudo, de evocaciones clasicistas del Renacimiento y del Neoclásico, imagen que perdura y sigue ocupando hasta hoy un lugar central.

Incluso en el periodo de las vanguardias históricas, observa Juan Vicente Aliaga, los artistas -varones en su inmensa mayoría, e independientemente de su adscripción o inclinación política, pues el discurso machista atraviesa las diferentes posiciones ideológicas, desde la más conservadora a la más progresista-, siguieron en su obra reforzando la imagen de la mujer como objeto pasivo, «dominada por la mirada de su creador, sojuzgada por su inactividad, adscrita a funciones subordinadas, paralizada por el mismo proceso de objetualización, convertida en un pedazo de carne» (2007: 31) [5].

Podríamos preguntarnos si actualmente, cuando las imágenes que construyen los patrones de la feminidad lo hacen principalmente a través de los medios masivos de comunicación, tienen todavía importancia los monumentos. Hagamos un poco de historia.

La ciudad moderna, derivada de los postulados racionalistas, abomina del monumento. Existe al respecto una cita de Walter Benjamin verdaderamente demoledora: «Un criterio para comprobar si una ciudad es moderna: la ausencia de monumentos» (2004: 391).

Pero la extensión del modelo funcionalista sufrió un veloz proceso de degradación al ser explotada al máximo de sus posibilidades por parte de la especulación inmobiliaria, dando lugar a unos barrios inhóspitos, carentes de referencias simbólicas, lo que acabará, ya a mediados de los años 60 del siglo XX, provocando el regreso de la escultura pública, en un intento de dotar de algún matiz de reconocimiento, de identidad al (anti)urbanismo anónimo del hormigón armado. El problema va a ser que, durante esos años de exilio del espacio público, la escultura moderna había evolucionado en una dirección (la autonomía de la obra de arte) que hará que aterrice -o se estrelle- en las plazas igual que un me- 


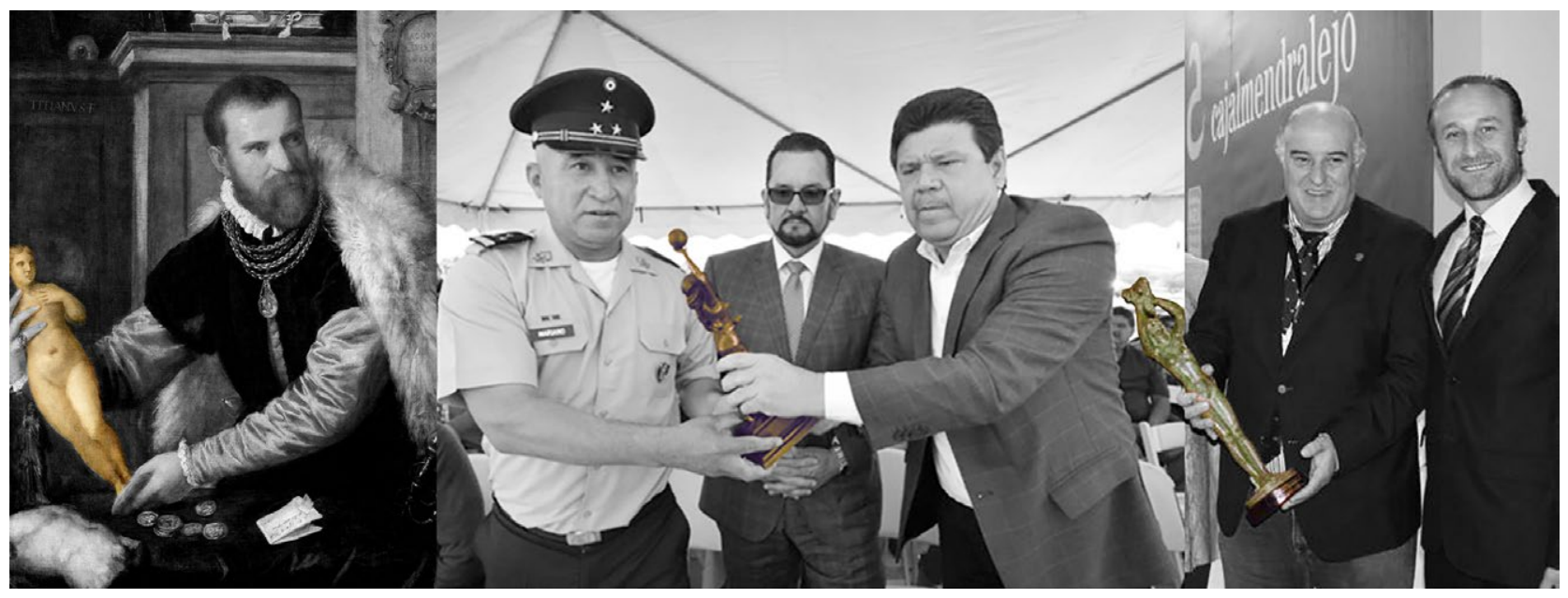

6. Trofeos. Tiziano, Jacopo Strada, 1561 h, Kunsthistorisches Museum. Viena (Austria). Entrega de trofeos realizados a partir del Monumento a la Mujer, Mexicali (México), 2015. Premio Musa de la Vendimia (reproducción de una obra de Juan de Ávalos) otorgado por la Cámara de comercio de Badajoz y el Ayuntamiento de Almendralejo en el Salón del Vino y la Aceituna de Almendralejo (Badajoz), 2013

teorito, como un ovni, como un objeto procedente de una galaxia extraña, sin la menor relación formal ni conceptual con el entorno, rompiendo totalmente la semántica del lugar y del espacio (Lippard, 2001: 61).

Careciendo de valores conmemorativos o simbólicos, además de hacer uso de códigos francamente minoritarios, ante su negación, por principio, a establecer un diálogo con el contexto espacial ni hacer referencia a otra cosa que a su mismidad, la instalación de la escultura moderna en el espacio público, salvo contadas excepciones, ha constituido un fiasco; y, ante este fracaso, ante la incomprensión del público, las viejas estatuas van a regresar; al amparo, sí, de la orgía del ladrillo y de la turistización de las ciudades, pero vinculadas además a una recuperación de la historia entendida como un elemento de ideologización, basado en la reivindicación de una cultura vernácula, popular y populista, que apela a los más básicos sentimientos de identificación y pertenencia.

Andreas Huyssen ha observado el paralelismo existente entre la vieja pasión monumental decimonónica y el "giro cultural hacia el pasado» propio de nuestra época: la búsqueda de un anclaje que proporcione sustento y durabilidad a un mundo inestable y que se transforma velozmente. Para «garantizar la permanencia y brindar la protección tan deseada contra la aceleración del tiempo» y la transitoriedad
(2007: 176), se tiende a la utilización de referencias icónicas sólidas, como el monumento (de apariencia) tradicional lo que, inevitablemente, conlleva una poderosa carga ideológica, pues «los medios no transportan la memoria pública con inocencia» sino que «la configuran en su estructura y en su forma misma» (Huyssen: 2007: 26).

Y en esa llamada al orden que representa el retorno de las estatuas a los espacios públicos urbanos, los parques y rotondas se han llenado otra vez de cuerpos de mujeres parcial o totalmente desnudos, como si las imágenes de cuerpos femeninos incorporasen ya belleza por sí mismas, mejorando, con su mera presencia, la calidad del espacio público; del mismo modo que el cuerpo de una joven embellece y ennoblece el acto o el lugar en que aparece, se trate de una entrega de trofeos a un héroe de deporte o un premio a un tiburón de las finanzas [6].

La abundancia en los monumentos públicos de cuerpos femeninos con carácter de ornato, de «bello complemento", contrasta con su exclusión sistemática del lugar y la memoria (Durán, 2008: 63). Contados son los monumentos dedicados a mujeres concretas, identificadas individualmente, destacando, de acuerdo con la misma tradición que declara como «ejemplares» a los héroes masculinos, las excepcionales heroínas de la llamada guerra de la Independencia (Agustina de Aragón), que hacen uso de la misma retórica 


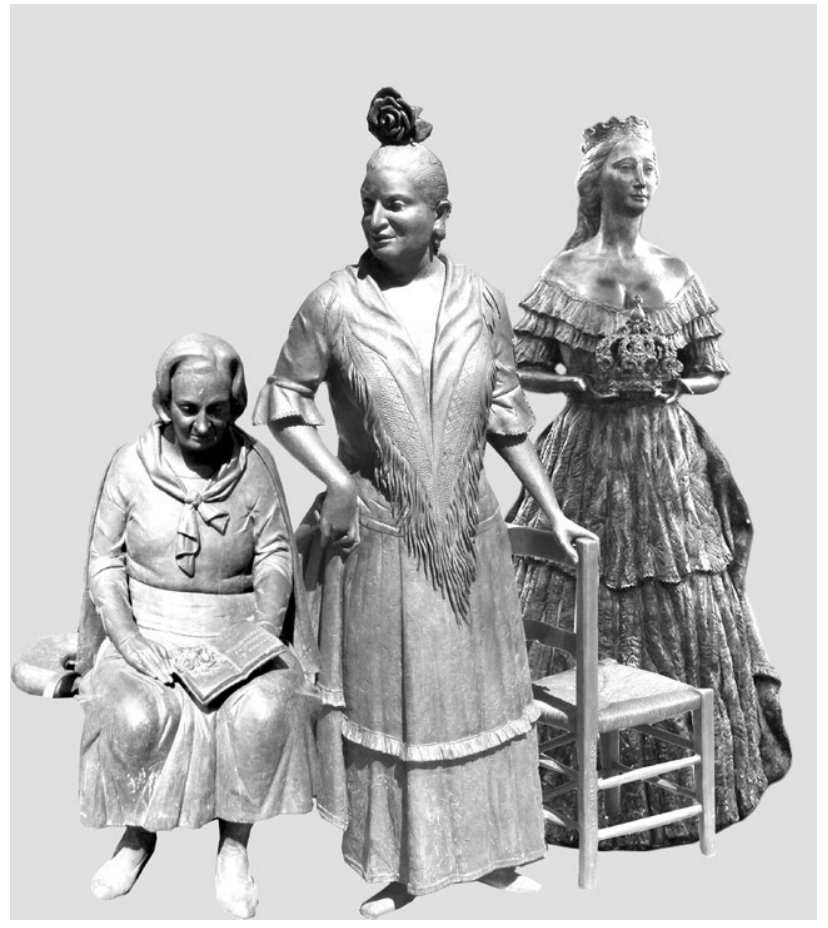

7. Elena Martín Vivaldi, obra de José Antonio Castro Vílchez, Eugenia de Montijo, obra de Miguel Barranco López, María la Canastera, obra de José Antonio Castro Vílchez. Granada, 2010

que los monumentos de la independencia de las repúblicas americanas, a su vez inspirados en la tradición republicana francesa. Prácticamente único es el caso de Mariana Pineda, paradigma de la heroína liberal, figura no fácilmente asimilable por parte del pensamiento conservador.

Muy recientemente, en los últimos años del siglo $X X$ y las primeras décadas del $X X I$, se percibe una intención de incorporar de un modo $u$ otro a las mujeres a los monumentos, añadiendo a la nómina de personajes monumentalizados personalidades femeninas del mundo de la alta cultura, aunque también han proliferado los monumentos dedicados a mujeres del mundo del espectáculo (actrices o cantantes)4. A estos dos grupos habría que sumar una serie de estatuas dedicadas a personajes famosos, habituales en la llamada prensa rosa o del corazón, que enlazan, además, con la más antigua tradición monumental, por su pertenencia a la realeza o la nobleza, pero marcados por sus gustos o actitudes populistas (por ejemplo, Cayetana Fitz-James, la duquesa de Alba, o doña María de las Mercedes de Borbón). Es inte- resante constatar que en el caso del paquete de diez estatuas inauguradas de golpe en el bulevar de la Constitución en Granada, en 2010, las tres mujeres granadinas homenajeadas encarnan esos tres modelos: la escritora, Elena Martín Vivaldi; la profesional del espectáculo, la bailaora María la Canastera; y la aristócrata «popular», Eugenia de Montijo [7].

La escasez de mujeres célebres, o que quienes erigen los monumentos consideran celebrables, no deja de ser un reflejo de la desproporción de su número dentro de la categoría patriarcal de «eminencias» dignas de reconocimiento público. Es muy significativa a este respecto la monumentalización de personajes femeninos, con nombre propio pero sin existencia real; homenajes a mujeres de ficción, creadas por la imaginación de autores varones: Carmen, Dulcinea, la bella Lola, etc. Podríamos relacionar este fenómeno con el mito de la «musa inspiradora», de cuya persistencia son ejemplo el siguiente par de monumentos.

El primero, inaugurado en Madrid en 1972, como homenaje a Ramón Gómez de la Serna, que reproduce el rostro del escritor en un medallón, rodeado de objetos alusivos a su mester: una lira, unos libros, una máscara de teatro, sus plumas estilográficas, etc., y sobre todo ello una figura femenina que, desnuda y con los brazos en alto, alude a la «anticipación», a la «vanguardia» del escritor.

El otro, mucho más reciente, desde 2011 honra en Sevilla «a la Generación del 27». La imagen icónica de este grupo poético es un retrato tomado aquel año en el Ateneo de Sevilla, durante un homenaje a Góngora, en el que aparecen solamente hombres. Y solo varones son los más destacados miembros que de este grupo se suelen citar: Vicente Aleixandre, Pedro Salinas, Jorge Guillén, Gerardo Diego, Federico García Lorca, Rafael Alberti, Dámaso Alonso, Vicente Aleixandre, Luis Cernuda, Emilio Prados, Manuel Altolaguirre, etc. Solo muy recientemente, y a duras penas, se han ido incorporando los nombres de algunas mujeres, como Concha Méndez, María Teresa León, Ernestina de Champourcín, Josefina de la Torre, etc. Sin embargo, más de ochenta años después de la famosa foto, en la imagen dominante de aquel momento la mujer continúa ausente y, si aparece, lo hace todavía en calidad de musa inspiradora: el conjunto monumental del que hablamos consiste en una fuente ornamental y una cascada como metáfora del nacimiento del «río de la poesía», representada por la figura de una joven desnuda [8]. 


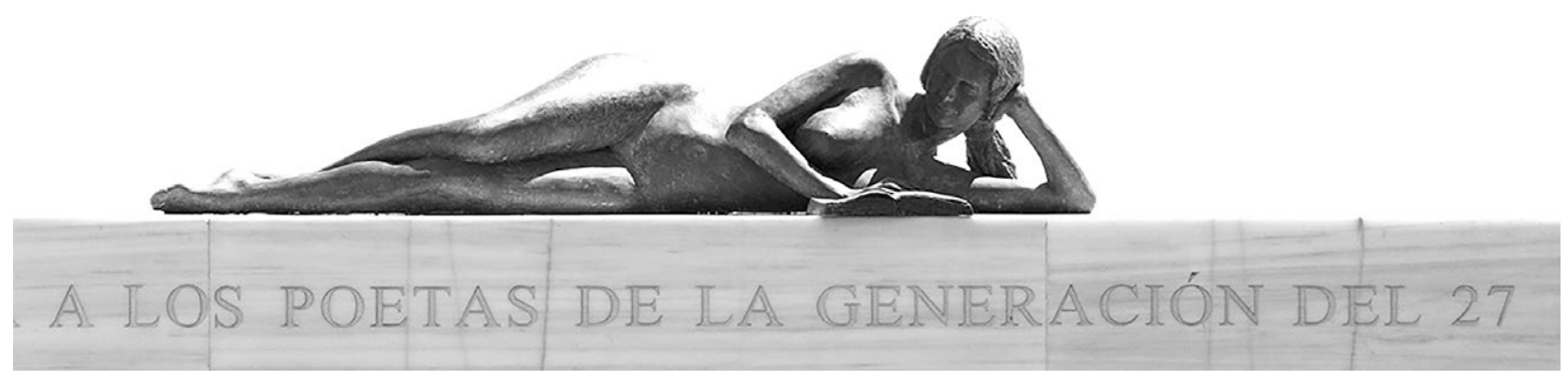

8. A la Generación de 1927, César Portela, 2011, Sevilla

Por otra parte, desde no hace mucho menudean los monumentos «de amplio espectro», dedicados de modo indiscriminado "a la mujer», memoriales que en algunos casos ven recargado su significado mediante la celebración en ellos de actos en homenaje a las víctimas de la violencia de género, a quienes también se dedican, por otra parte, monumentos específicos. Es oportuno detenerse aquí en la función de encubrimiento que pueden llegar a cumplir los monumentos, ya que los homenajes de este tipo, como los minutos de silencio y las actas de sesiones de los ayuntamientos, ponen en evidencia que la liberación de una violencia de carácter estructural no puede resolverse por decreto, ni mediante actos simbólicos de solidaridad, pues nada hay que pueda sustituir al indispensable compromiso político colectivo para su erradicación, lo que pasa por una transformación radical, estructural, de la educación, de la economía, del mercado de trabajo, etc., sin olvidar la revolución necesaria en el ámbito de los afectos y los cuidados, pues este trabajo no reconocido ni remunerado que ejercen las mujeres es un pilar fundamental del sistema capitalista; sin él, colapsaría. Y para evitarlo, las mujeres son educadas en la noble misión de dedicar su vida al bienestar ajeno: parir, cuidar de la casa, de los niños, del esposo, los enfermos, los ancianos...

Si bien es cierto que, como asevera Eli Bartra, «hablar de la condición de la mujer es un acto político» y que igualmente político es no hacerlo, pues «omitir hablar de las mujeres es igual a mentir» (1994: 38); es preciso puntualizar que las prácticas culturales feministas han de ser «necesariamente deconstructivas, en el sentido de que funcionen para cuestionar las bases de las normas existentes» (Nead,
2013: 103). Así, las operaciones de inclusión en la nómina de los monumentos públicos de homenajes a mujeres famosas o, genéricamente, «a la mujer», o «a la mujer trabajadora», requieren ser observados con más detenimiento. Veamos algunos ejemplos.

En el caso de los monumentos a mujeres trabajadoras, estas siguen viéndose relegadas a labores históricamente feminizadas, como cuando se las representa preparando alimentos: una guisandera, una vendedora de castañas asadas, las queseras, etc.

Las actividades laborales mayoritariamente ejercidas por las mujeres en esta lógica patriarcal no van a ser aquellas que precisen de estudios y de formación profesional, sino más bien trabajos de tipo manual, como los relacionados con la agricultura y el cuidado de los animales domésticos, actividades tradicionalmente complementarias de la economía familiar: monumentos a una vendedora de gallinas, a las vendimiadoras, a las olivareras, vendedoras de pescado, sardineras, conserveras; o siguiendo con el hilo, nunca mejor dicho, de las actividades vinculadas a la producción y conservación de los tejidos: una mujer encajera, una costurera, las lavanderas, etc. $Y$ también hay monumentos dedicados a ensalzar la angustia de «la mujer del marinero» que espera preocupada en tierra su regreso.

Hay que llamar la atención sobre otro aspecto: estos sentidos homenajes a la mujer trabajadora tienden a representar acciones localizadas temporalmente en el pasado, lo que se subraya mediante la vestimenta o el carácter obsoleto de los utensilios que aparecen manejando. En un gesto que se dirige a la excitación de sentimientos de índole nostálgica, se idealiza algo que ha desaparecido y que solo 


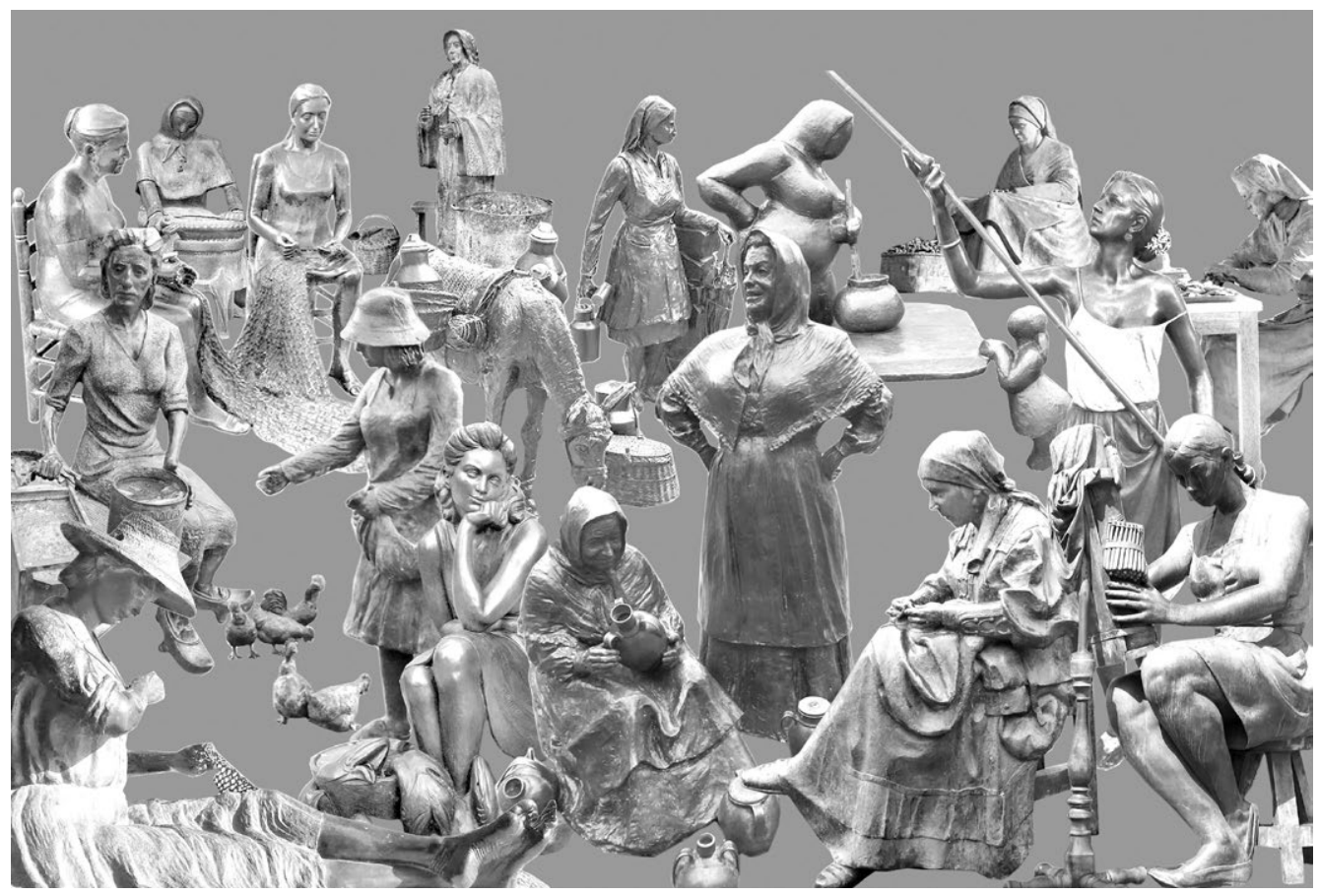

9. Colección III: Trabajadoras. Redera, José Miguel Mas Valls, 1999, Valencia. Pescadera, Sebastián Miranda, 2005, Oviedo. Vendedoras del Fontan, Amado González Hevia "Favila», 1996, Oviedo. Costureras de la Vega, José Luis Marrero Cabrero, 2009, Vega de San Mateo (Gran Canaria). Encajera o la puntaire, Josep Viladomat, 1972, Barcelona. Regadora de los patios, José Manuel Belmonte, 2014, Córdoba. Vendedora de gallinas, Cuqui Piñeiro, 2009, Pontevedra. Conservera, J. A Barquín, 2002, Santoña (Cantabria). Dones Remendadores, Maria Dolors Ortuño, 1998, Cambrils (Tarragona). Castañera, Daniel Calvo Péres, 1999, Palencia. Castañera, Xoxe Cid, 2001, Orense. Lechera, Manuel Garcia Linares, 1996, Oviedo. Guisandera, M. ${ }^{a}$ Luisa Sánchez Ocaña Fernández, 2000, Oviedo. Pementeira, Ramón Conde, 2002, Padrón (La Coruña). Conservera, Pepe Gómez, 2003, Ayamonte (Huelva)

podemos imaginar a través de reproducciones, sean documentales o, como en el caso de los monumentos, ficticias. La proyección de estos sentidos homenajes hacia un tiempo pretérito, en un tono de compensación meramente simbólica, de agradecimiento por los servicios prestados, parece perseguir, como efecto secundario y no inmediatamente perceptible, que se dé por cumplida, con ese gesto, la obligación de reconocimiento del trabajo femenino más real e inmediato [9].

La idealización, en suma, a la que los monumentos someten al objeto de su homenaje suele implicar un enmascaramiento de su complejidad, en aras de su simplificación y de la neutralización de sus posibles aristas conflictivas. De ahí que se repita con frecuencia el recurso de monumentalizar algo que ya no existe, o que está en trance de desapa- rición, o que la nostalgia ha estetizado hasta convertirlo en una atracción de tipo turístico.

El 8 de marzo de 2002, la Concejalía de la Mujer del Ayuntamiento de Granada, movida por la voluntad de corregir la ausencia de mujeres en los monumentos, inauguró un monumento dedicado "a la mujer joven del siglo XXl», que representa a una adolescente en pose relajada y vestida con una malla de ballet. Se trata de un ejemplo modélico de la construcción de un discurso oficial «políticamente correcto» por parte de las instituciones públicas respecto a «la mujer». Pero esa intención de dar fe de los cambios y la situación real de la presencia de las mujeres en la sociedad actual, el intento de reflejar más fielmente la realidad social colisiona con la contradicción de que esa «aspiración igualitaria» pasa por alto el hecho de que ser una mujer, o un 
10. Julia, obra de Antonio Santín. Intervención con pintura morada en 2003, Madrid

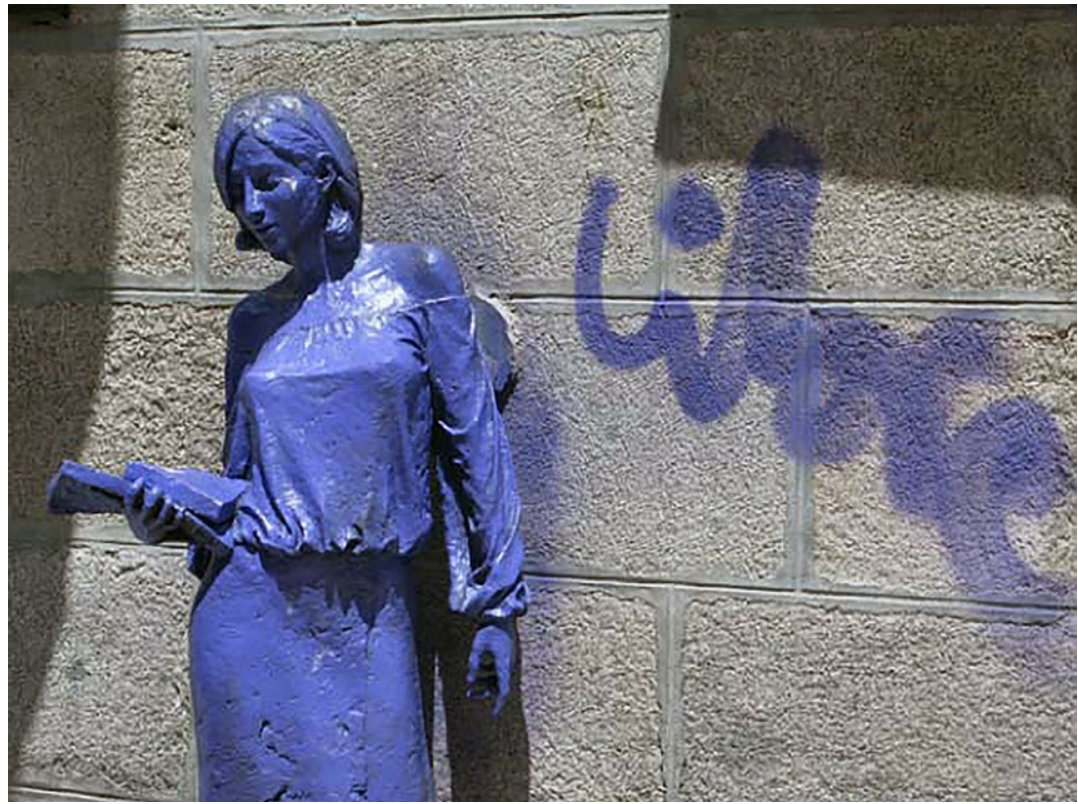

hombre, no es nunca algo simple y evidente por sí mismo e invariable, ignorando también cómo esas identidades se ven atravesadas por otras formas de identidad y discriminación, como la raza o la clase social. Los derechos de las mujeres no pueden ser pensados abstractamente, al margen de la crítica de una estructura social que es fruto del sistema capitalista y patriarcal en marcos culturales específicos. Además, el monumento se inserta formalmente en la tradición androcéntrica de representación académica del cuerpo femenino: la adolescente ballerina como paradigma de una feminidad marcada por la gracilidad y la delicadeza; por la debilidad, en suma, de cuerpos obligatoria y recalcadamente jóvenes y esbeltos.

Una vez más, una pregunta retórica ¿de qué sirven las grandilocuentes proclamas oficiales basadas en el discurso de la igualdad de género en medio del flujo ininterrumpido de mensajes que, a través de otros medios menos explícitos, más sutiles y, por tanto, más eficaces, afirman, muestran y hasta demuestran, lo contrario?

El «deber de belleza» ${ }^{5}$ que el espacio público parece exigir a las mujeres encuentra en estas imágenes alegóricas una humanización fantasmagórica y una estética petrificada, que en el caso de los monumentos dedicados a mujeres «reales» se va, llamativamente, a subdividir: las actrices y cantantes aparecerán representadas en el esplendor de su juventud, mientras que las intelectuales -científicas o escritoras- lo harán en forma de virtuosas matronas en su madurez, e incluso como venerables abuelas asexuadas. Recordemos los monumentos por ejemplo a Elena Martín Vivaldi en Granada o a Rosa Chacel en Valladolid. La representación como ancianitas de estas mujeres, inteligentes, cultas e independientes, puede acabar generando no identificación, sino incluso antipatía por parte de mujeres más o menos jóvenes que podrían ver en ellas una referencia, un modelo. La elección de un periodo o momento u otro de la vida de la persona homenajeada no es una reproducción más o menos acertada del personaje, sino que contribuye a fabricar su imagen pública, la produce.

Con respecto a la representación de los cuerpos femeninos como «objeto contemplado», la evidencia de su carácter político la convierte en un campo de batalla crucial, dado que es a través suyo como se ejerce lo que el sociólogo Pierre Bourdieu ha llamado «violencia simbólica», por la cual se impone un tipo de coerción muy poderoso y eficaz sobre los sometidos, puesto que estos se ven imposibilitados no ya de ofrecer resistencia sino ni siquiera de pensar su condición misma, expropiados de los instrumentos indispensables para interpretar, para visibilizar la relación de dominio. 
Como respuesta, como contestación a su pretensión de "decir la última palabra», pueden interpretarse las reacciones iconoclastas de que son objeto los monumentos, sean más o menos ambiguas o explicitas en su intencionalidad, se trate de expresiones con pintura roja sobre el rostro del monumento a la duquesa de Alba, a los pocos días de su inauguración, en 2011, en Sevilla; o las agresiones sufridas por una serie de esculturas de bronce que, representando a jóvenes mujeres que «se pasean» a pie de calle por el barrio de Malasaña en Madrid, que han sido objeto de ataques, entre ellos, uno que bañó a la estatua titulada «Julia» de pintura violeta, acompañando la acción de un grafiti con la palabra «libre». Todo parece indicar la existencia de mujeres descontentas con su aire de pasiva modestia, pudor y timidez [10].

Los medios de comunicación tienden a ignorar las posibles connotaciones ideológicas de estas acciones, despachándolas rápidamente bajo el epígrafe de «vandalismo»; como en su tiempo, en 1913, lo fueran los destrozos que algunas de las primeras sufragistas -Annie Briggs, Evelyn Manesta y Lillian Forreste- causaron en los cuadros de la Sala de los Prerrafaelitas en la Manchester Art Gallery, como protesta por el modo en que las mujeres aparecían en ellos. Una actitud que no puede ignorarse en otra célebre acción de la lucha sufragista: el atentado realizado un año más tarde por otra sufragista, Mary Richardson, contra la Venus del Espejo de Velázquez en la National Gallery de Londres.

Hay que recordar, de nuevo con Griselda Pollock, que las imágenes no son meros síntomas de causas externas a ellas mismas (capitalismo, patriarcado, sexismo, etc.) sino que desempeñan un papel activo en la producción de estas categorías: al tiempo que representan un mundo cargado de significación, articulan y producen significados, y en el caso de las representaciones de las mujeres, "seducen a las personas del género femenino a reconocerse a sí mismas en estos signos y lugares» (1991: 85-90). La elección de una u otra imagen no es inocente, pues no representa de un modo más o menos fiel la realidad, sino que toma parte activa en su construcción. El análisis y el desvelamiento de la función política de las representaciones constituyen una tarea fundamental en los procesos de identificación de la violencia simbólica, un empeño indispensable de la lucha de las mujeres por su emancipación.

\section{Notas}

1 Una reflexión que anota Walter Benjamin en su Diario de Moscú respecto a esta ciudad en su estancia de dos meses (1926-1927): «una de las causas fundamentales de su belleza: en ninguna de sus espaciosas plazas se ve monumento alguno» contrastándola con las ciudades europeas donde «apenas existe plaza alguna que no haya sido profanada y vulnerada en su estructura más íntima, a lo largo del siglo XIX, con algún monumento» (1990: 85).

2 En el control de esos cuerpos reside, como describe el antropólogo Claude Meillasoux en Mujeres, graneros y capitales, la primera acumulación originaria: si no hay suficientes mujeres, el grupo no puede reproducirse ni sobrevivir. Igual que las vestales guardan el fuego sagrado de la ciudad, que simboliza la protección del hogar, el cuerpo de las mujeres, como la patria, como la nación, ha de ser defendido por fronteras estrictas que no admitan la intromisión de extraños. Véase también Silvia Federici, Calibán y la bruja. Mujeres, cuerpo y acumulación originaria.

3 Lynda Nead en su libro El desnudo femenino: arte, obscenidad y sexualidad, hace una productiva relectura crítica del clásico libro publicado por primera vez en 1956 de Kenneth Clark, El desnudo, donde traza la historia del desnudo desde la antigüedad griega. Clark asume de modo automático, con naturalidad que está hablando de un desnudo femenino y un espectador masculino. Muy significativamente el libro lleva como subtítulo Un estudio del arte ideal.

4 Las artes en que destacan estas estrellas no dependen tanto del estudio, el trabajo o el esfuerzo -o al menos no son socialmente percibidas de ese modotanto como de una especie de gracia innata, un don. Algo natural como la belleza. Los monumentos a estas figuras suelen tener en común el hecho de representar a las artistas en un momento de plenitud física, de esplendor juvenil y de hermosura. A diferencia de la edad elegida para las escritoras, por ejemplo. El arte de la mujer, como todas sus virtudes, le viene dado por naturaleza.

5 En el año 2003 fue inaugurada en Córdoba una fuente que incluye las estatuas de dos mujeres jóvenes con sendos cántaros que se titula Homenaje a la belleza de la mujer cordobesa. Es significativa la decisión de escoger un tema como el mito de la belleza de la mujer local, popularizado en el siglo XX a partir de la peculiar obra pictórica de Julio Romero de Torres.

\section{Bibliografía}

ALIAGA, Juan Vicente (2007), Orden fálico. Androcentrismo y violencia de género en las prácticas artísticas del siglo XX, Ediciones Akal, Madrid.

BARTRA, Eli (1994), Frida Kahlo. Mujer, ideología y arte, Icaria editorial, Barcelona. 
BAUDELAIRE, Charles (1995), El pintor de la vida moderna, Colegio Oficial de Aparejadores y Arquitectos Técnicos, Cajamurcia, Librería Yerba, Murcia.

BENJAMIN, Walter (1990), Diario de Moscú, Taurus, Buenos Aires.

- (2004), El libro de los pasajes, Akal, Madrid.

BORDO, Susan (1991), «Material Girl: The Effacements of Postmodern Culture», en GOLDSTEIN, Laurence (ed.), The Female Body Figures, Styles, Speculations, University of Michigan Press, Ann Arbor, pp. 106-130.

BOURDIEU, Pierre (2003), La dominación masculina, Anagrama, Barcelona.

BURKE, Peter (2005), Visto y no visto. El uso de la imagen como documento histórico, Editorial Crítica, Barcelona.

CLARK, Kenneth (1956/1996), El desnudo: Un estudio de la forma ideal, Alianza editorial, Madrid.

DUQUE, Félix (2001), Arte público y espacio político, Ediciones Akal, Madrid.

DURÁN, María Ángeles (2008), La ciudad compartida. Conocimiento, afecto y uso, Ediciones Sur, Santiago de Chile.

ERICE SEBARES, Francisco (2008), Guerras de la memoria y fantasmas del pasado: usos y abusos de la memoria colectiva, Editorial Eikasia, Oviedo.

FEDERICI, Silvia (2013), Calibán y la bruja. Mujeres, cuerpo y acumulación originaria, Traficantes de sueños, Madrid.

GONZÁLEZ, Ana Isabel, «Violencias de género constitutiva de crímenes de lesa humanidad y genocidio: El caso de Guatemala». En: <http:// www.memoria.fahce.unlp.edu.ar/art_revistas/pr.6431/pr.6431.pdf> (fecha de consulta: 13-3-2015).

HUYSSEN, Andreas (2007), En busca del tiempo perdido. Cultura y memoria en tiempos de globalización, Fondo de Cultura Económica, Buenos Aires.

LIPPARD, Lucy R. (2001), «Mirando alrededor: dónde estamos y dónde podríamos estar», en BLANCO, Paloma; CARRILLO, Jesús; CLARAMONTE, Jordi y EXPÓSITO, Marcelo (eds.), Modos de hacer. Arte crítico, esfera pública y acción directa, Ediciones Universidad de Salamanca, pp. 51-72.

MEILLASSOUX, Claude (1987), Mujeres, graneros y capitales, Siglo XXI, México.

NEAD, Lynda (2013), El desnudo femenino: arte, obscenidad y sexualidad, Tecnos, Madrid.

NOCHLIN, Linda (1971/2007), «¿Por qué no han existido grandes artistas mujeres?», en CORDERO, Karen y SÁNCHEZ, Inda (comps.), Crítica feminista en la teoría e historia del arte, UNAM-IBERO, México, pp. 17-44.

POLLOCK, Griselda (1991), «Mujeres ausentes (un replanteamiento de antiguas reflexiones sobre imágenes de la mujer)», Revista de Occidente, n. ${ }^{\circ} 127$, diciembre, pp. 85-90.

SEGATO, Rita (2010), «La violencia sexual y el discurso del derecho», en SONDERÉGUER, María y CORREA, Violeta (comps.), Violencia de género en el terrorismo de Estado: políticas de memoria, justicia y reparación, Cuaderno de Trabajo CEDHM-Centros de DDHH, Universidad Nacional de Quilmes, Universidad Nacional de Lanús, Buenos Aires.

YUVAL-DAVID, Nira (2004), Género y Nación, Flora Tristán, Lima. 
